Research, part of a Special Feature on Do we need new management paradigms to achieve sustainability in tropical forests?

\title{
Sustainability of Mangrove Harvesting: How do Harvesters' Perceptions Differ from Ecological Analysis?
}

\author{
Laura López-Hoffman $^{1}$, Ian E. Monroe ${ }^{2}$,Enrique Narváez ${ }^{3}$, Miguel Martínez-Ramos ${ }^{1}$, and \\ David D. Ackerly ${ }^{4}$
}

\begin{abstract}
To harvest biological resources sustainably, it is first necessary to understand what "sustainability" means in an ecological context, and what it means to the people who use the resources. As a case study, we examined the extractive logging of the mangrove Rhizophora mangle in the Río Limón area of Lake Maracaibo, in western Venezuela. The ecological definition of sustainable harvesting is harvesting that allows population numbers to be maintained or to increase over time. In interviews, the harvesters defined sustainable harvesting as levels permitting the maintenance of the mangrove population over two human generations, about 50 yr. In Río Limón, harvesters extract a combination of small adult and juvenile trees. Harvesting rates ranged from 7-35\% of small adult trees. These harvesting levels would be sustainable according to the harvester's definition as long as juvenile harvesting was less than $40 \%$. However, some harvesting levels that would be sustainable according to the harvesters were ecologically unsustainable, i.e., eventually causing declines in mangrove population numbers. It was also determined that the structure of mangrove forests was significantly affected by harvesting; even areas harvested at low, ecologically sustainable intensities had significantly fewer adult trees than undisturbed sites. Western Venezuela has no organized timber industry, so mangrove logs are used in many types of construction. A lagging economy and a lack of alternative construction materials make mangrove harvesting inevitable, and for local people, an economic necessity. This creates a trade-off between preserving the ecological characteristics of the mangrove population and responding to human needs. In order to resolve this situation, we recommended a limited and adaptive mangrove harvesting regime. We also suggest that harvesters could participate in community-based management programs as harvesting monitors.
\end{abstract}

Key Words: conservation; tropical forest; sustainable management; Venezuela.

\section{INTRODUCTION}

Conservation biologists now recognize that social and ecological systems must be linked, and local and scientific knowledge integrated, to develop ecologically resilient and sustainable communitybased management programs (Berkes and Folke 1998, Becker and Ghimire 2003, Brown 2003). Biological resources can only be sustainably managed when scientific knowledge of population structures, abundances, and growth rates are integrated with the knowledge of the local people who use these resources (Berkes et al. 1998, Mackinson and Nottestad 1998, Turner et al. 2000,
Armitage 2003, Brown 2003, Moller et al. 2004). Recently, however, several authors have argued that the term "sustainable" is vague (Newton and Freyfogle 2005a,b). They maintain that it is essential to ask the following questions: What is being sustained? By whom? For whom? Over what time period? We believe that to sustainably manage biological resources it is first important to understand what sustainable means both ecologically and to the people who use the resources. Only when contrasting meanings of sustainability are clearly defined can community-based management programs be developed that link social and ecological systems. 
Here we examine the extractive logging of the mangrove Rhizophora mangle in the Río Limón area of Lake Maracaibo, Venezuela as a case study for understanding the concept of sustainability from both biological and social perspectives. First, we studied the effects of harvesting on mangrove forest structure, and modeled the effects of harvesting on population dynamics to understand sustainability from an ecological perspective. We asked the following question, "What is the effect of harvesting on forest structure and the long-term fate of the mangrove population." We used field surveys of harvested plots to determine harvesting rates and the effects of harvesting on forest structure. We studied the dynamics of an undisturbed mangrove population to understand the mangrove population's potential resilience to harvesting. We surveyed forest plots to determine the range of harvesting intensities in the region. Matrix population projection models were then used to simulate harvesting and (Usher 1969a,b), and matrix elasticity analysis was used to detect vulnerable mangrove population elements in which harvesting has the most impact on mangrove population growth (de Kroon et al. 1986).

Second, we interviewed local harvesters about their local knowledge and to determine how they understand the concept of sustainability. We asked them if they thought it important to sustainably harvest the mangroves, and to define the time frame over which the mangrove resource should be sustained. We inquired if they thought that current levels of mangrove harvesting were sustainable. We asked for their opinion of what makes mangroves resilient or susceptible to harvesting. Finally, we inquired about harvesting practices, and whether the availability of the mangrove resource had changed over time. Biological knowledge of mangrove population dynamics and an ecological interpretation of sustainability were then compared with the harvesters' knowledge and definition of sustainability. The ultimate goal of this project was to provide local people and managers with sufficient information about the ecology and social context of mangrove harvesting for the development of an ecologically and socially integrated community-based mangrove management program.

\section{METHODS}

\section{Study site and species selection}

The Río Limón mangrove forests of Lake Maracaibo (10,900 ha) are Venezuela's fourth largest mangrove system (Galue and Nucette 1982, Conde and Alarcón 1993). They are located 50 km northeast of Maracaibo, Venezuela's third largest city. Two of the four species of mangrove present in the area, Laguncularia racemosa and $R$. mangle are harvested for logs. These species are restricted to low intertidal, low salinity areas. Here we focus on $R$. mangle because it is the most common (Narváez 1998) and the most commonly harvested species (López-Hoffman and Narváez, personal observation).

\section{Historical and sociological background}

For centuries, indigenous groups have used logs from the mangroves of Lake Maracaibo to build canoes and palafitos, stilt huts (Conde and Alarcón 1993). Western Venezuela has no organized timber industry, so today mangrove logs are used in many types of construction, from palafitos to the scaffolding used to build homes, stores, and office buildings in Maracaibo and other nearby large cities. In the 1970s, the Venezuelan government became alarmed at the rapid rate of mangrove decline and decreed that all remaining mangroves would be government-owned lands (Lacerda 2002). Although mangrove harvesting is now illegal, the Venezuelan National Guard does not appear to have sufficient resources to enforce mangrove protection. In the Río Limón area, mangrove stands within 1-2 km of the National Guard station are not harvested, although harvesting is common in more removed areas (López-Hoffman and Narváez, personal observation).

Mangrove logs are harvested by small groups of 26 men using machetes. Each group of harvesters has plots of mangrove forest that they harvest on a regular basis, but the plots do not legally belong to the harvesters. Rather, there are informal agreements between harvesters about who has the right to harvest a given plot. After cutting, mangrove logs are transported by boat to nearby communities where they are sold. Most logs are sold directly by the harvesters, but there are middlemen who buy logs and resell them in the nearby city of Maracaibo at higher prices. Historically, only rural and 
indigenous people harvested mangroves, but increasingly, urban people are engaging in harvesting. Conversations with local officials indicate this may be due to lax enforcement, a lagging economy, and a lack of alternative construction materials. For most harvesters, fishing is their primary source of income, and mangrove harvesting is secondary; some urban harvesters engage in other activities. The mangroves of Lake Maracaibo been shown to be vital for the maintenance of healthy shrimp and fish stocks (Gil et al. 2003). In addition to logs, the only other direct usage of mangroves that has been observed is the collection of honey from hives in A. germinans trees.

\section{Interviews with harvesters}

In July and August 2001, we interviewed 23 harvesters from the urban community of El Moján and 12 and 5 from the rural communities of Puerto Paez in Laguna de Sinamaica and Maraca Island, respectively. The subjects were between 22 and 92 $\mathrm{yr}$ of age (mean $=47.6, \mathrm{SD}=6.3 \mathrm{yr}$ ), and had between 1 and $66 \mathrm{yr}$ of harvesting experience (mean $=21.3, \mathrm{SD}=17.1 \mathrm{yr}$ ). In 2002, the parish of San Rafael, where El Moján is located, had a population of 54,282, most living in or around the town (OCEI 2002). In 1992, Puerto Paez and Maracas Island had populations of 372 , of which 200 were men, and 233, of which 125 were men, respectively (OCEI 1992). Most rural men harvest mangroves at least occasionally. We do not know how many urban men harvest mangroves. Rather than determine the number of potential harvesters in the region, we wanted to understand how those who do harvest perceive the sustainability of harvesting.

The anonymous interviews were conducted at local meeting places for fishermen and harvesters. We interviewed all the harvesters present at the time of our visit in the late afternoon or early evening. We used both the semidirected interview and the questionnaire suggested by Huntington (2000) for assessing local knowledge. In the semidirected interview, we inquired about the harvesters' belief systems; we asked the harvesters about the importance of sustainable harvesting, to define sustainability, and if they thought current harvesting levels were or were not sustainable, we asked why or why not. In the questionnaire, we asked for quantitative assessments of harvesting practices and perceived changes in mangrove resource availability over time (Table 1). Examples of harvesting practices are the number of $\operatorname{logs}$ extracted on a daily basis and number of months waited before returning to harvest a given site (Table 1). Given that the Venezuelan National Guard rarely enforces mangrove protections and because the interviews were anonymous, we do not believe the subjects were hesitant to give frank answers.

Principal components analysis (PCA) based on a correlation matrix of standardized variables, appropriate for mixed sets of ordinal and continuous variables (ter Braak 1987), was used to analyze the questionnaire data, using PC-Ord (MjM Software Design, Gleneden Beach, OR, USA, Version 4 for Windows). We consider only eigenvectors with eigenvalues greater than 1 . The interview subjects were categorized as younger ( $<40 \mathrm{yr}$ of age) or older $(40+y r)$. We had originally intended to compare the attitudes and harvesting practices of urban vs. rural harvesters, but detected few important differences, so do not make this distinction in the analyses presented. The study was not designed to test for age differences, but these turned out to be the most significant factor explaining differences in respondents' answers. A description of the variables is provided in Table 2 .

\section{Mangrove demography: the population dynamics of undisturbed mangrove forests}

For 2 yr from June 1999 to June 2001 we followed the growth, survivorship, and fecundity of $R$. mangle individuals in five life history stages in undisturbed forest stands. These data were used to parameterize a stage-based matrix population projection model for understanding the dynamics of undisturbed mangrove forests and for simulating the effects of harvesting. We established $60 \times 10 \mathrm{~m}$ transects, eight in total, in three sites that were not harvested because they were near the National Guard station. The sites were $0.5-2 \mathrm{~km}$ from one another. All sites were in low salinity, low intertidal areas, and subject to approximately the same inundation and salinity regimes, with seasonal variation between $0-15 \%$ of full seawater (Narváez 1998). The five stage classes were: seedlings ( $\mathrm{S}:<$ $70 \mathrm{~cm}$ height), juveniles ( $\mathrm{J}:>70 \mathrm{~cm}$ height and $<2$ cm dia.), small adults (A1: $2-14.9 \mathrm{~cm}$ dia.), medium adults (A2: 15-29.9 cm dia.), and large adults (A3: $30+\mathrm{cm}$ dia.). A life cycle flux diagram (Fig. 1) shows the density of each class/ha, the sampled number of individuals/class, and the geometric mean transition rates and arithmetic mean fecundity 
Table 1. Descriptions of the six questionnaire variables used in the principle components analysis (PCA) ordination. The type of variable, and whether the variable was log-transformed is noted.

\begin{tabular}{llc}
\hline \hline Variable & \multicolumn{1}{c}{ Question/Description } & Type of Variable \\
\hline $\begin{array}{l}\text { Trends in } \\
\text { average daily } \\
\text { harvests }\end{array}$ & $\begin{array}{l}\text { Have average daily harvests Increased (3), Decreased (1) or Stayed the } \\
\text { Same (2) overtime? }\end{array}$ & Ordinal \\
$\begin{array}{l}\text { Combined dist- } \\
\text { ance }\end{array}$ & $\begin{array}{l}\text { Has the combined distance (by boat and walking) traveled to find suitable } \\
\text { mangroves Increased (3), Decreased (1) or Stayed the Same (2) overtime? }\end{array}$ & Ordinal \\
$\begin{array}{l}\text { Difficulty } \\
\text { Has the difficulty of finding mangroves suitable for harvesting Increased }\end{array}$ & Ordinal \\
$\begin{array}{l}\text { Experience } \\
\text { (3), Decreased (1) or Stayed the Same (2) overtime? } \\
\text { harvest }\end{array}$ & Years of experience harvesting mangroves. & Continous (Log) \\
Return & Present day average daily harvest. & Continous (Log) \\
& Number of months waited before returning to harvest at the same site. & Continuous (Log) \\
\hline
\end{tabular}

values of the 2 yr. Appendix 1 details the model parameterization and analysis.

We used elasticity analysis to identify the mangrove population's most vulnerable components. Elasticity analysis describes the relative sensitivity of population growth rate, $\lambda$, to changes in each transition element (de Kroon et al. 1986). Demographic elements with high elasticity may indicate a population's most vulnerable components, in which harvesting will have the greatest impact and conservation efforts may be most effective (Silvertown 1987, Caswell 2000).

The matrix models do not consider densitydependent effects or environmental feedbacks, such as the creation of gaps in the tree canopy caused by harvesting. Although moderate increases in light availability have been shown to increase $R$. mangle seedling growth (López-Hoffman et al. 2006), large gaps may change soil salinity, temperature, and $\mathrm{pH}$, possibly negatively impacting seedling development (Hamilton and Snedaker 1984, Smith 1992). Future demographic studies should examine gap feedbacks.

\section{Mangrove demography: the effect of harvesting}

The first step in assessing the effect of harvesting was to develop a method for determining when a tree stump had been cut. We identified two harvester informants from El Moján with 67 and 52 yr of harvesting experience. The use of key informants, often local leaders, is recommended in studies of local knowledge (Huntington 2000). The informants showed us the stumps of trees they had harvested previously. We observed the decomposition of 15-20 stumps cut in each of the previous $7 \mathrm{yr}$, and developed a classification scheme for determining when a stump was harvested (Table 1). All the observed tree stumps were located in low intertidal, low salinity areas.

Our second step was to determine the range of harvesting intensities in the region. We asked the leaders of the mangrove harvesters in the three communities to define, based on their experience, three harvesting levels, Low (no to low harvesting), Medium, and High. We established 20 quarter-ha plots $(50 \times 50 \mathrm{~m}), 6$ each at Low and Medium, and 8 at High Intensity. All plots were located in low 
Table 2. Criteria used to estimate the length of time since a stump was harvested.

\begin{tabular}{|c|c|c|c|c|c|c|c|}
\hline Character & $1 \mathrm{yr}$ & $2 \mathrm{yr}$ & $3 \mathrm{yr}$ & $4 \mathrm{yr}$ & $5 \mathrm{yr}$ & $6 \mathrm{yr}$ & $7 \mathrm{yr}$ \\
\hline $\begin{array}{l}\text { Trunk attach- } \\
\text { ment to } \\
\text { ground/ sturdi- } \\
\text { ness }\end{array}$ & $\begin{array}{l}\text { Very sturdily } \\
\text { anchored in } \\
\text { the ground }\end{array}$ & $\begin{array}{l}\text { Still sturdily } \\
\text { anchored in } \\
\text { the ground }\end{array}$ & $\begin{array}{l}\text { Trunk very } \\
\text { slightly loose }\end{array}$ & $\begin{array}{l}\text { Possible to } \\
\text { rock the } \\
\text { trunk slightly. } \\
\text { Thick roots } \\
\text { are still } \\
\text { firmly attached }\end{array}$ & $\begin{array}{l}\text { Trunk will } \\
\text { move around } \\
\text { in the ground, } \\
\text { but it's still } \\
\text { not possible } \\
\text { to pull out of } \\
\text { the ground }\end{array}$ & $\begin{array}{l}\text { Trunk easy to } \\
\text { pull out of } \\
\text { the ground }\end{array}$ & $\begin{array}{l}\text { Hardly anchored } \\
\text { in the ground. } \\
\text { May just be } \\
\text { resting on its } \\
\text { prop roots }\end{array}$ \\
\hline
\end{tabular}

\begin{tabular}{|c|c|c|c|c|c|c|c|}
\hline Small roots & Not brittle & $\begin{array}{l}\text { Starting to } \\
\text { dry, not easy } \\
\text { to break }\end{array}$ & $\begin{array}{l}\text { Dry and } \\
\text { fairly easily } \\
\text { broken }\end{array}$ & $\begin{array}{l}\text { Break off } \\
\text { easily }\end{array}$ & $\begin{array}{l}\text { May crumble } \\
\text { easily }\end{array}$ & $\begin{array}{l}\text { Crumble easily } \\
\text { or no longer } \\
\text { present }\end{array}$ & $\begin{array}{l}\text { Often no } \\
\text { longer present }\end{array}$ \\
\hline Large roots & Not brittle & $\begin{array}{l}\text { Roots still } \\
\text { sturdily attac- } \\
\text { hed }\end{array}$ & $\begin{array}{l}\text { Roots still } \\
\text { sturdily attac- } \\
\text { hed }\end{array}$ & $\begin{array}{l}\text { Roots are dry } \\
\text { and break } \\
\text { with force }\end{array}$ & $\begin{array}{l}\text { Roots are dry } \\
\text { and break } \\
\text { easily }\end{array}$ & $\begin{array}{l}\text { Roots dry } \\
\text { and easy to } \\
\text { break, but } \\
\text { thickest roots } \\
\text { are still } \\
\text { strong }\end{array}$ & $\begin{array}{l}\text { Only the } \\
\text { thickest roots } \\
\text { remain }\end{array}$ \\
\hline
\end{tabular}

Color under Green or root bark bright red

Color under $\quad$ Green or trunk bark bright red

Bark

Color of Yellow with Gray. exposed wood some gray on trunk

Wood wetness, peel bark with knife
Smooth and attached
No green left, Dark brown red color is now dark

No green left, May still be red color is dark red or now dark already dark brown

Dry and can Bark is be peeled off, but still attached

\section{cracking, but} will not peel off on its own crumbly

Dark brown or black

Dark brown or black

Dark brown or black

Dark brown or black

Dark brown or black

Dark brown or black
Dark brown or black

Dark brown or black 
Fig. 1. Life cycle flux diagram of the Rhizophora mangle baseline population. The boxes represent life history stages. Inside is the density of individuals/ha in each stage and sample size of individuals. The relative size of the boxes represents population density on a log scale. The arrows between boxes represent annual transition probabilities between stages (bold numbers). Circular arrows represent annual probabilities of permanence in same stage (italic figures). Arrows leaving boxes indicate yearly mortality rates (ind ind ${ }^{-1} \mathrm{y}^{-2}$ ). Circles above the adult stages represent the average number of established seedlings produced/tree, or fecundity. Total seedling density is the sum of all products of fecundity and adult density. The permanence, mortality, and transition rates are the geometric means of the data from 2 yr. The fecundity values are the arithmetic mean of the $2 \mathrm{yr}$.

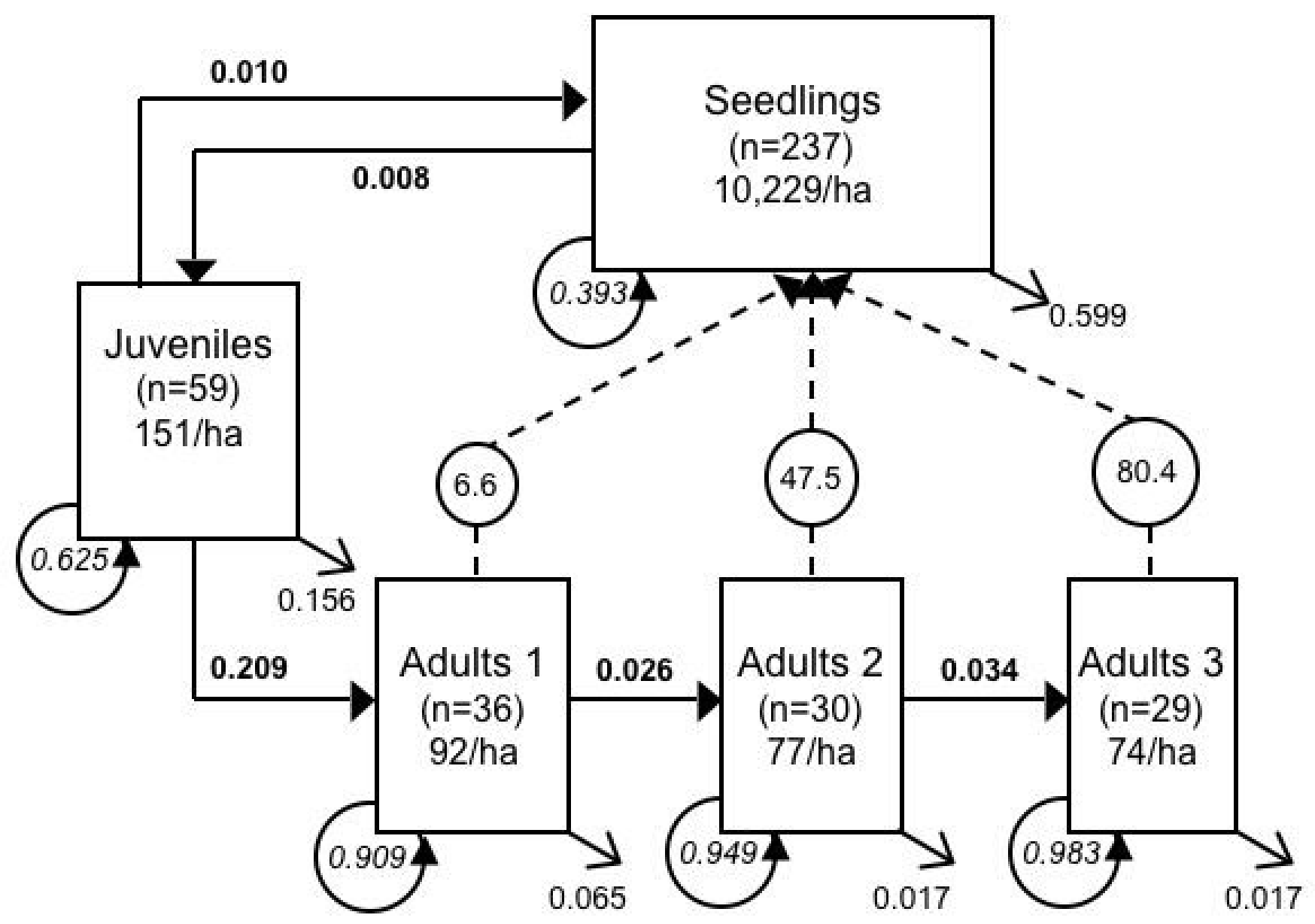

intertidal, low salinity areas, similar to the baseline stands. Within each plot, we counted all cut stumps and estimated the time since cutting. We also estimated the density of the remaining juveniles and adult trees. In each plot, the number of individuals cut/stage class/yr was determined by using the density estimates to reconstruct the original tree frequencies/stage class in each plot. We then calculated the geometric mean harvesting rate over $7 \mathrm{yr}$. We compared the average size structures of the forest stands at Low, Medium, and High harvesting intensities with the average forest structure of the undisturbed stands. The data were analyzed with a general linear model using GLIM 3.77 (Royal Statistical Society, London, UK) using a Poisson error and a logit link function (Crawley 1993).

We used a demographic approach to simulate the effects of harvesting on long-term population 
growth rates $(\lambda)$, in which harvesting is an additional source of mortality, i.e., a reduction in survivorship. The mathematical limit for sustainability is the harvest level when $\lambda$, the mangrove population growth rate, equals 1 , indicating a population in numerical equilibrium. Additional mortality will drive $\lambda$ below 1 , and the population will decline (Lefkovitch 1967, Usher 1969a,b). The essence of this criterion is that a sustainable harvesting regime permits the extraction of some individuals while maintaining or even increasing overall population numbers. Note that positive population growth, $\lambda>$ 1 , would eventually lead to density-dependent feedbacks limiting population size, and these are not incorporated in the matrix analysis.

We observed that most harvested trees were in the A1 size class, i.e., $<1 \%$ of harvested trees were A2, and no A3 trees were harvested, so we only considered A1 harvesting. We detected very few harvested juveniles, however, harvesters said that they cut significant numbers of juveniles. Juvenile stumps are thinner, and most likely decay faster than adult stumps. To account for juvenile harvesting in the simulations, we also calculated the sensitivity of $\lambda$ to $0-40 \%$ harvesting of juveniles. We simulated harvesting using the baseline data from each of the $2 \mathrm{yr}$, and report the geometric means for both $\lambda$ and $95 \%$ confidence intervals for $\lambda$ (see Appendix).

\section{RESULTS}

\section{Social context of harvesting: interviews with harvesters}

All 40 interviewed harvesters believe in the importance of sustainably harvesting the mangroves. Almost all agree that the period over which the mangrove resource should be sustained is two human generations. One harvester said, "We should leave enough mangroves for our grandchildren to be able to harvest." All of the harvesters believe that the current levels of mangrove harvesting are sustainable according to their definition.

Principal components analysis (PCA) was used to analyze the questionnaire data about harvesting practices and changes in mangrove resource availability over time. The first PCA axis for the questionnaire data was related to mangrove resource availability (Fig. 2). People at the higher end of Axis 1 reported that (1) the difficulty of finding mangroves to harvest and the combined distance they have to travel by boat and walking had increased over time and (2) over time, the average number of logs extracted/d had declined. In addition, people at the higher end of Axis $1 \mathrm{had}$ more years of experience harvesting mangroves (Fig. 2). In an ANOVA, Axis 1 scores were strongly associated with the age of the subject, with higher Axis 1 scores for older subjects (Fig. 2).

PCA Axis 2 was associated with the frequency of mangrove harvesting. Individuals who waited longer intervals before returning to harvest again at a given site, i.e., people who harvested less frequently, were at the higher end of Axis 2 (Fig. $2)$. There was a weak relationship $(P=0.078)$ between Axis 2 scores and age, suggesting that older harvesters returned less frequently than younger harvesters (Fig. 2), i.e., older harvesters harvested less intensively than younger harvesters.

We asked the harvesters if the mangrove resource could ever be depleted. Over $90 \%$ of those interviewed consider the mangroves to be inexhaustible, although a few conceded that in the future they might have to "look harder to find them." The harvesters gave a variety of answers when asked to specify why mangroves cannot be depleted (Fig. 3 ). Over $40 \%$ think that mangroves regenerate quickly enough to recover from harvesting. One experienced harvester said, "Cut 10,000 and $10,000,000$ will grow back." Four subjects thought that their management practices would prevent mangroves from being depleted: two said they did not cut small trees, and two said they did not cut large trees. Forty percent believe that mangroves reproduce quickly enough to repopulate themselves, i.e., $17 \%$ specifically mentioned that mangroves produce many seeds (Fig. 3).

Only three harvesters believed that the mangroves resource could be exhausted. All three expressed concerns that too many logs were being cut. One indicated that this was because too many houses were being built. Another responded that harvesters were cutting too many young trees, and that "they should wait until the trees are older." These three individuals were 24, 32, and 52 yr old.

\section{The demography of harvesting}

The population growth rate $(\lambda)$ of the undisturbed population was $\lambda=1.044(1.07,1.02,95 \% \mathrm{CI})$. This indicates an expanding population and suggests that 
Fig. 2. On top is a vector diagram of the principlal components analysis (PCA) ordination loading factors along Axes 1 and 2. Axis 1 is related primarily to aspects of mangrove scarcity. Axis 2 relates to harvesting intensity. The vector labels refer to the variables in Table 2. On the bottom is the PCA ordination of the 40 interview subjects based on the six response variables in Table 2. The labels indicate whether the subject was younger or older than $40 \mathrm{yr}$ of age. ANOVA values are reported for the effects of urban/rural status and age on PCA Axes 1 and 2 scores.

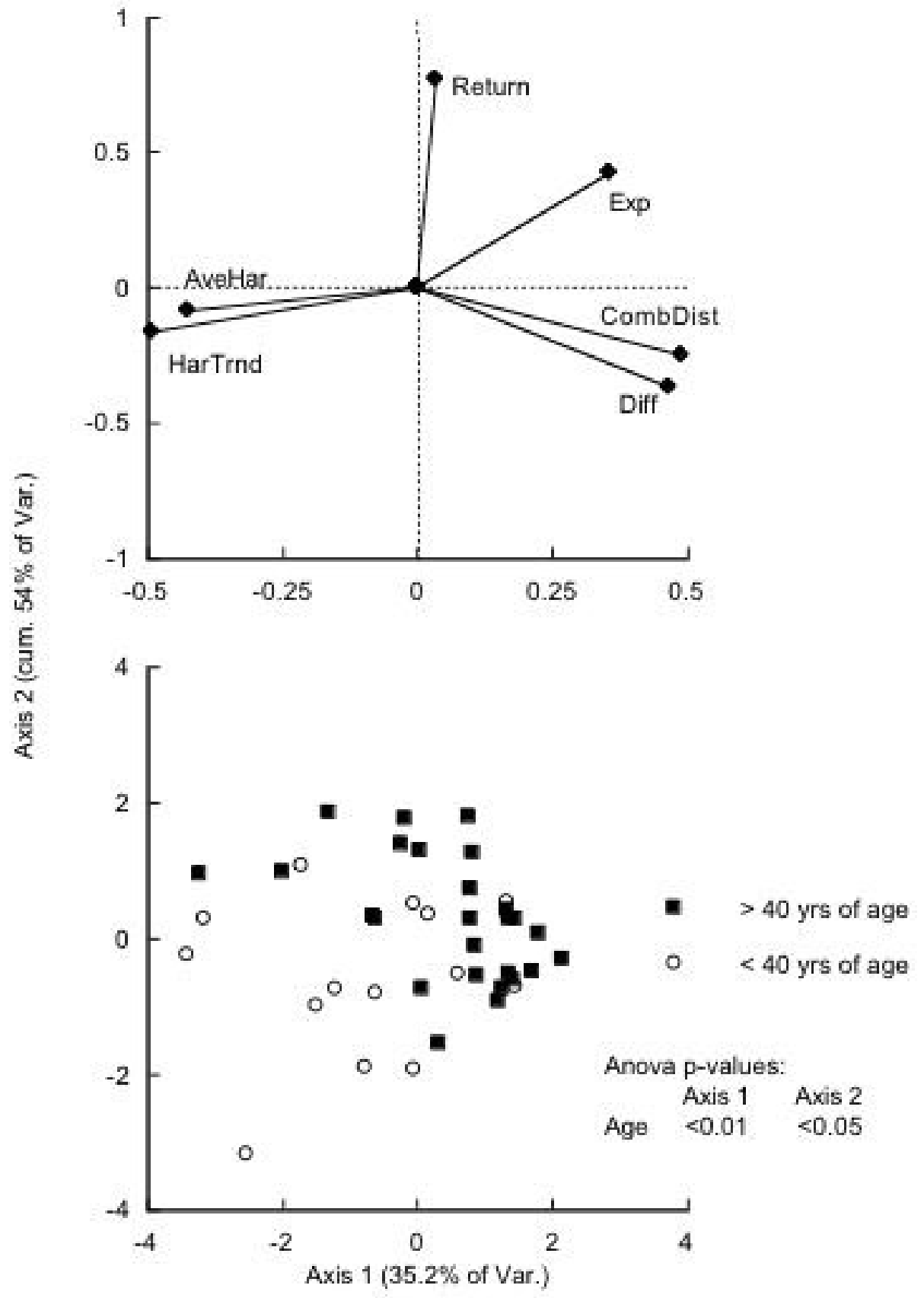


Fig. 3. Responses from the semidirected interviews of the 36 subjects who viewed mangroves as an inexhaustible resource when asked to specify why. The values exceed $100 \%$ because many subjects gave more than one explanation in their responses. The dark shading on the "Reproduces enough" column indicates people who specifically said that mangroves produce many seeds.

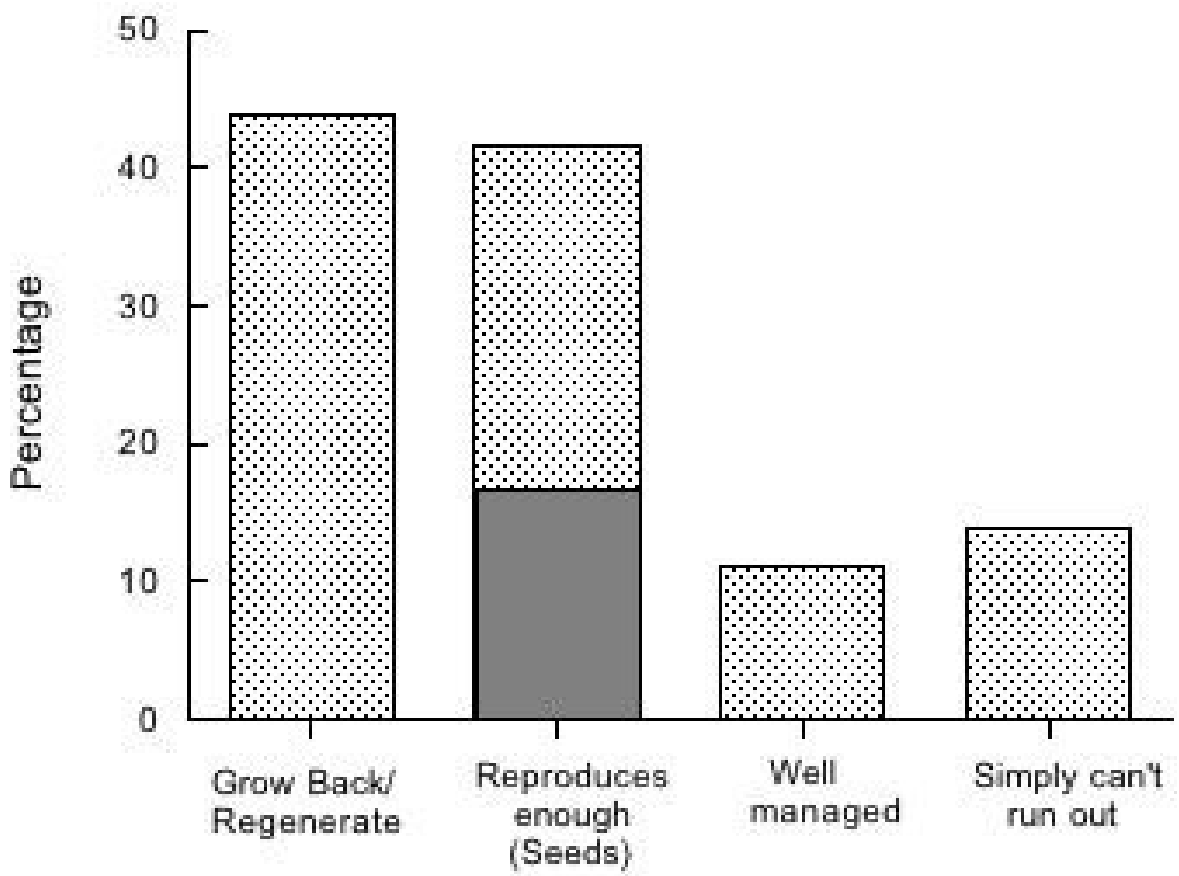

Answer

some harvesting can be sustained without causing population numbers to decline. We know of no other estimates of $\lambda$ for other $R$. mangle populations. The highest elasticity value was $34 \%$, for survivorship of A1 trees, followed by survivorship of the other adult classes. In contrast, the sum of the growth elasticities, i.e., transition from one stage to another, was less than $20 \%$, and the sum of the fecundity elasticities was $5.5 \%$ (Fig. 4). This elasticity structure is in agreement with the general pattern observed in woody plant populations; the highest elasticities are found in the survival component of adult stages, followed by growth and fecundity (Franco and Silvertown 1996). Elasticities may be used prospectively to project population growth trajectories following a disturbance (Caswell 2000), suggesting that changes in adult survivorship will result in the highest changes in population growth rates, whereas the population is mostly insensitive to changes in fecundity.
The annual harvesting rates of A1 adults ranged from $7.7 \%$ (SD 6\%) at the Low intensity sites to $23.9 \%$ (SD 2.9\%) to $33.4 \%$ (SD 2.6\%) at the Medium and High intensity sites, respectively. We also discovered one additional site where each year over the last seven years, $43.7 \%$ of A1 trees were harvested. There was a statistically significant effect of harvesting on stand structure $(P$ \&lt 0.05$)$. The Low, Medium, and High intensity sites had fewer adult individuals than the undisturbed stands (Fig. $5)$.

The amount of harvesting that can be sustainably applied to the mangrove population depends on the combination of juveniles and A1 individuals removed (Fig. 6). In the simulation analysis, some harvesting levels had mean $\lambda$ values below 1 , but $95 \%$ confidence limits that ranged above 1 (Fig. 6). To be statistically conservative, we consider these harvesting levels to be potentially sustainable. 
Fig. 4. Elasticity values for transition elements, or the relative contribution of each transition element to $\lambda$, the finite population growth rate at stability. Because the elasticities of $\lambda$ to all of the elements in a matrix sum to $100 \%$, the elasticity of $\lambda$ to a given element may be interpreted as the relative importance of that element to $\lambda$. The transition elements are on the horizontal axis. The survivorship, growth, and fecundity elasticities are labeled. The stage classes are abbreviated as follows: $\mathrm{S}$ is for seedlings, $\mathrm{J}$ is for juvenile, and A1, A2, and A3 are for Adults 1, 2, 3, respectively. S-S means seedling survivorship and permanence in the seedling size class. S-J means seedling to juvenile transition. A1-S means the fecundity of the A1 size class. Values are the means of 2000 bootstrap runs.

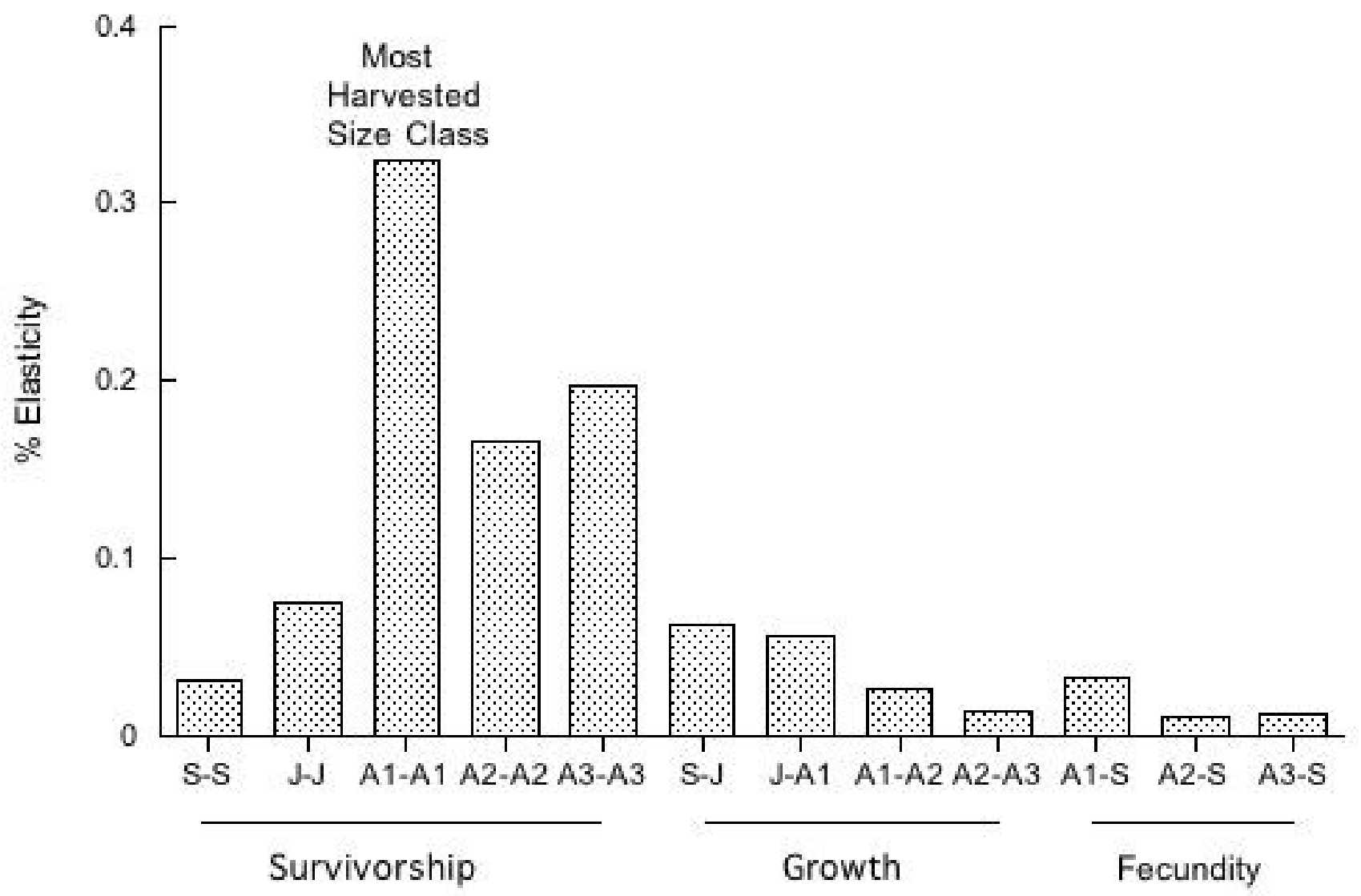

Transition Element

Using these criteria, with no juvenile harvesting, up to $40 \%$ of A1 individuals can be harvested sustainably. If $10 \%$ of juveniles are harvested, A1 harvesting should be limited to about $30 \%$. A $20 \%$ rate of juvenile harvesting means only $20 \%$ of $\mathrm{A} 1$ harvesting is sustainable. A $40 \%$ rate of juvenile extraction should limit A1 harvesting to $10 \%$ (Fig. $6)$.
The harvester's definition of sustainable harvesting was sustaining the mangrove resource for two human generations, or about 50 yr. For heuristic purposes, we interpret their definition of sustainability as allowing up to a 50\% reduction the mangrove population over $50 \mathrm{yr}$. Figure 7 shows the number of years of sustained harvesting that can be applied before causing a $50 \%$ reduction in mangrove population numbers. The analysis 
Fig. 5. Comparison of the size structure of the undisturbed population with the average structures of the stands at Low, Medium, and High harvesting intensities. Harvesting had a statistically significant effect on stand structure $(P<0.05)$. The stage classes are abbreviated as follows: $\mathrm{J}$ is for juvenile, and A1, A2, and $\mathrm{A} 3$ are for Adults 1,2,3, respectively.

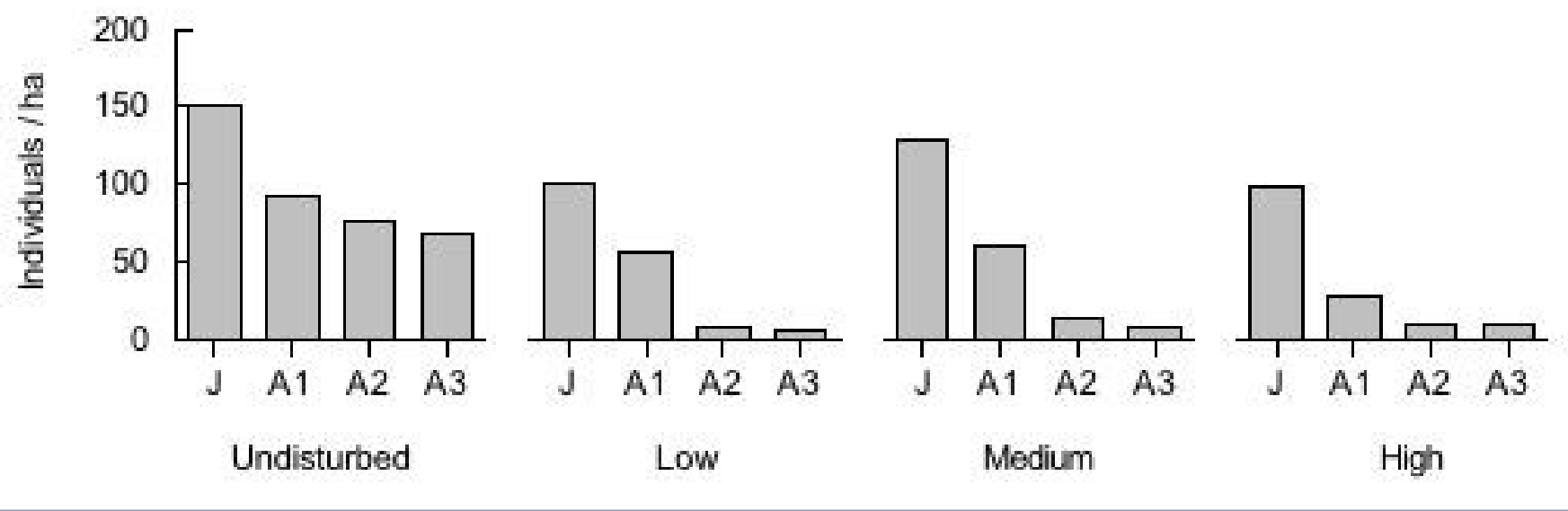

considers only those harvesting levels in Figure 6 that were considered statistically unsustainable, $\mathrm{i}$. e., both the mean $\lambda$ and the $95 \%$ CIs are below 1 . Using the criteria of sustaining $50 \%$ of the population for $50 \mathrm{yr}$, three harvesting levels that were considered ecologically unsustainable according to the analysis in Fig. 6, might be considered sustainable according to the harvesters' definition (Fig. 7).

\section{DISCUSSION}

What are the ecological effects of harvesting?

The mangrove forests are clearly being affected by harvesting as even Low intensity sites have significantly fewer adults than do the undisturbed sites. Our finding that adult trees are relatively less frequent in harvested areas is supported by the harvesters' observations that they currently have to travel farther to find A1 size trees than they did in the past. It is possible that local extirpation of A1 trees is occurring in areas easily accessible to harvesters. The mangroves of the national park, Ciénaga de los Olivitos, across Lake Maracaibo from Río Limón, also have skewed stage structures in heavily harvested areas. The park, which is easily accessible to harvesters, appears depopulated of small and intermediate $R$. mangle adults (LopezHoffman, personal observation).

Are current harvesting rates ecologically sustainable? Ideally, it would be useful to know the mean regional extraction rate. However, time and funding constraints did not allow for random sampling to estimate a regional rate, or for understanding the spatial patchiness of harvesting. We do know that annual harvesting rates of small adult trees range from $7.7 \%$ at the Low intensity sites to $23.9 \%$ and $33.4 \%$ at the Medium and High intensity sites, respectively, and may be as high as $44 \%$ in some areas. The mangrove population response to harvesting depends on the exact combination of juveniles and small adults extracted. Even though the precise levels of juvenile harvesting are unknown, our analyses suggest that some harvesting is sustainable.

It is important to be conservative when identifying a sustainable harvesting scheme because a regime that reduces $\lambda$ to 1 , leaves the population "balanced on an extinction knife-edge" (Caswell 2001). In such populations, uncertainty in parameter estimation or environmental and demographic stochasticity increases the likelihood that a population will be inadvertently driven to a precariously low level (Caswell 2001). The Low intensity harvesting level is sustainable as long as 
Fig. 6. Simulated effect of $0-100 \%$ A1 harvesting on the population growth rate, $\lambda$, including a sensitivity analysis of the effects of harvesting between $0-40 \%$ of juveniles. Values are the mean and 95\% confidence intervals (CIs) of 2000 bootstrap simulation runs. The Low, Medium, and High harvesting intensities are labeled. Harvesting levels with mean $\lambda$ values below 1 , but with $95 \%$ CIs that range above 1 , are considered to be sustainable. With no juvenile harvesting, up to $40 \%$ of A1 individuals can be harvested sustainably. If $10 \%$ of juveniles are harvested, A1 harvesting should be limited to about $30 \%$. A $20 \%$ annual rate of juvenile harvesting means only $20 \%$ of A1 trees should be harvested. A $40 \%$ rate juvenile extraction should limit A1 harvesting to $10 \%$.

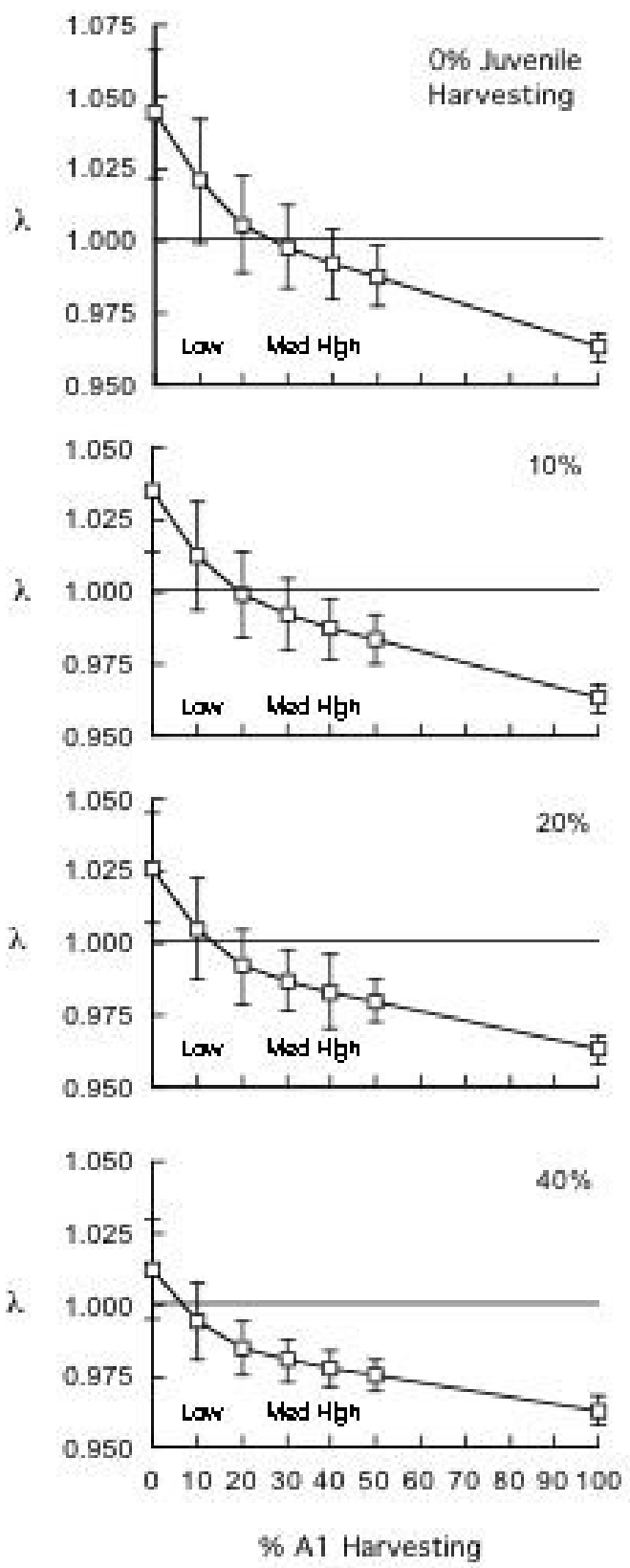


Fig. 7. The number of years of sustained harvesting that can be applied before causing a $50 \%$ reduction in mangrove population numbers. The analysis considers only those harvesting levels in Fig. 6 that were considered statistically unsustainable, i.e., both mean $\lambda$ and $95 \%$ CIs are entirely below 1 . Using the criteria of sustaining $50 \%$ of the population for $50 \mathrm{yr}$, three harvesting levels that were considered ecologically unsustainable according to the analysis in Fig. 6 might be considered sustainable according to the harvesters' definition.
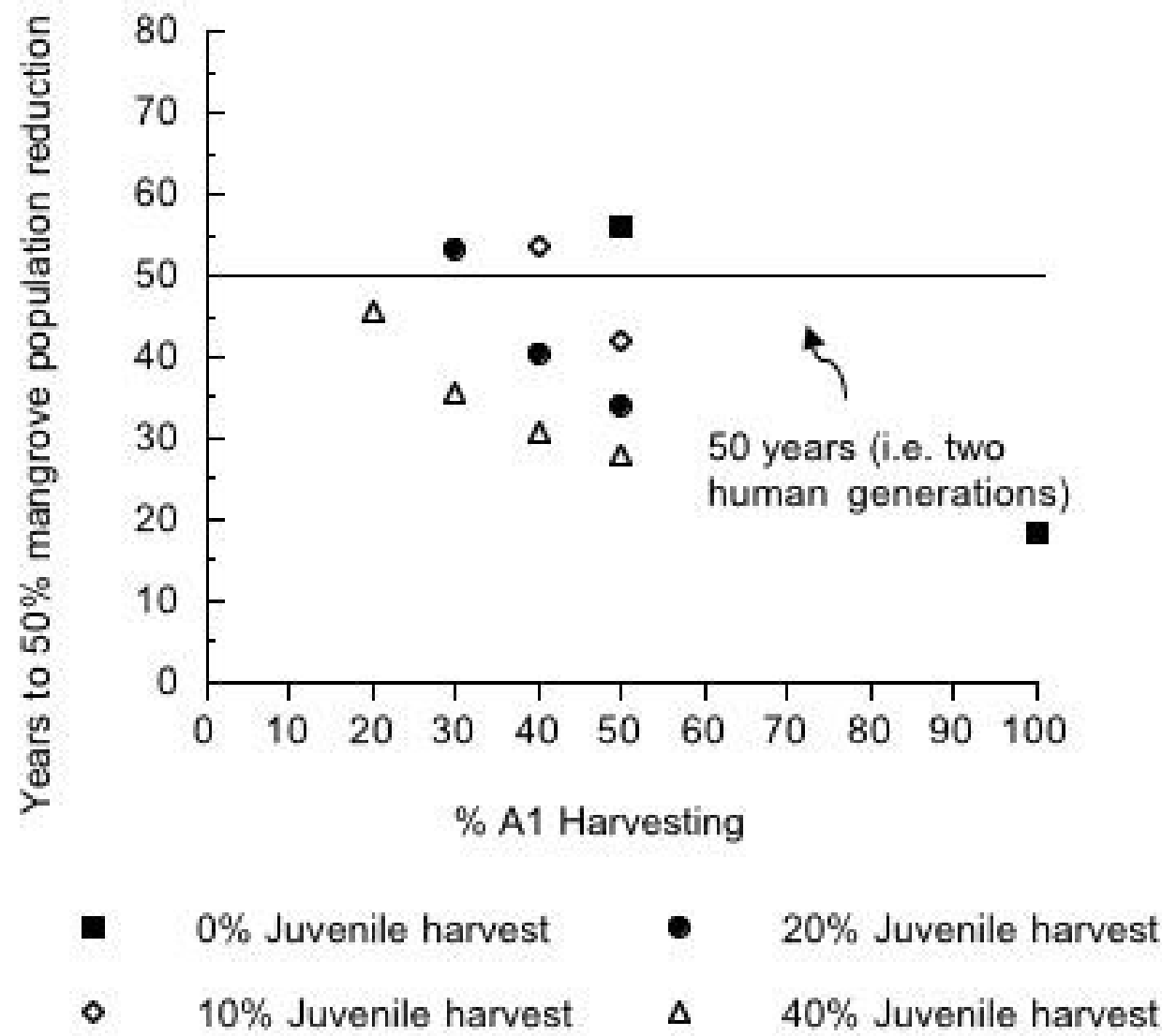

juvenile harvesting does not greatly exceed $40 \%$; juvenile extraction rates greater than $40 \%$ are unlikely. Medium intensity is sustainable if juvenile harvesting does not exceed $10 \%$. High intensity may not be sustainable according to Caswell (2001), and the highest harvesting rate observed, $44 \%$, is clearly unsustainable.

The definition of ecologically sustainable harvesting employed thus far in this paper is harvesting that allows population numbers to be sustained or even increase over time. Even in an ecological context this definition may be limited. First, if the ecological goal is to determine a harvesting rate that leaves the harvested population unchanged, it may be unachievable (Struhsaker 1998). In this study, even stands harvested at low rates, which permitted the maintenance of positive population growth, had significantly altered size structures. Furthermore, this definition of sustainable considers only the effect of harvesting on the target species $R$. mangle; it does not consider the effects on the entire mangrove system (e.g. Newton and Freyfogle 2005a,b). A more inclusive ecological characterization of sustainability would consider the effects of $R$. mangle harvesting on other mangrove tree species, on the animals and insects who nest in $R$. mangle trees, and the marine 
organisms who use the mangrove as breeding grounds.

Are current harvesting levels sustainable according to the harvester's concept of sustainability? The harvesters defined sustainable harvesting as permitting the maintenance of mangrove population numbers over two human generations, about $50 \mathrm{yr}$. According to the field surveys, most harvesting ranges in intensity from $7-35 \%$ of A1 trees. These harvesting levels are sustainable according to the harvester's definition as long as juvenile harvesting rates are less than $40 \%$. However, some harvesting levels that are sustainable according the harvesters, are ecologically unsustainable, i.e., eventually causing declines in mangrove population numbers.

What are the age differences between harvester knowledge and harvesting practices?

Local knowledge is heterogeneous; often, not all members of the given area or community have the same ecological knowledge (Gadgil et al. 2000, Brown 2003, Ghimire et al. 2004). We discovered that age explained most variation in harvester knowledge. It appears that older individuals harvested less intensively than younger harvesters; they harvested fewer $\operatorname{logs} / \mathrm{d}$, and waited longer before returning to harvest a given site. Differences in physical strength might explain the difference in daily harvesting rates, but do not explain why young men returned more frequently to harvest a particular site. It also appeared that older men were more selective in their harvesting practices, taking only the most desired tree sizes. One 52-year-old harvester noted that younger harvesters "are destroying the mangrove, cutting immature trees and not letting them grow. In the past, the mangrove was all shady, but now it has gaps because of cutting."

Older harvesters than younger harvesters perceived declines in mangrove abundance over time. Obviously, this could be due to experience, i.e., number of years harvesting, as age and experience were correlated $\left(R^{2}=0.50, P<0.01\right)$. However, it is curious that even the older harvesters who had been harvesting mangrove for only a few years noted trends in scarcity. This could be due to conversations with their more experienced contemporaries. It is possible young men do not spend much time with older men, making it difficult for older harvester's knowledge to be transmitted to younger men. Many authors have noted that intergenerational information transmission is extremely important to the preservation of local conservation knowledge (Alcorn and Toledo 1998, Gadgil et al. 2000). It is also possible that younger harvesters are more assimilated into contemporary culture than older harvesters, diminishing their ecological knowledge (Turner et al. 2000).

Why is there a discrepancy between the local harvesters perceptions of sustainability and ecological analysis?

As discussed above, for some harvesters, their definition and the ecological definition of sustainability are simply different. However, it is possible that some harvesters are actually harvesting according to both the sociological and ecological notions of sustainability. The low intensity plots are harvested according to the ecological definition of sustainability. From the interview data, it is clear that older men harvest less intensively than do younger men. It is possible that older men are harvesting their plots in an ecologically sustainable manner whereas younger men are not. In addition, local knowledge about sustainable ecological practices is sometimes ignored under situations of economic need (Ghimire et al. 2004). The lagging economy and the lack of alternative construction materials may make mangrove harvesting a profitable and seemingly necessary activity. Although some harvesters may realize that harvesting levels are ecologically unsustainable, their economic situation might compel them to harvest in an ecologically unsustainable manner.

Why is there a discrepancy between local and scientific knowledge with respect to what makes mangroves susceptible or resilient to harvesting?

The harvesters extract small adult trees, which according to the elasticity analysis are the most important and vulnerable element of the mangrove population, while stating that fecundity, a relatively unimportant demographic element, can compensate for the effects of harvesting. According to the models, a $167 \%$ increase in fecundity would be necessary to offset the effect of harvesting only $12 \%$ of A1 adults. An increase in fecundity of this magnitude is unlikely under natural conditions. It is understandable that harvesters identify fecundity as a mechanism for resilience to harvesting. Mangroves have high reproductive output and high rates of seedling establishment, which might lead to the assumption that fecundity can compensate for 
intense harvesting. This is similar to the effort to protect Caretta caretta sea turtles, when natural resource managers and scientists mistook the importance of fecundity. Prior to performing demographic analyses, conservation efforts had focused on fecundity, i.e., the protection of nests and eggs, and hatchling survival as ways to increase population growth. Using elasticity analysis, it was determined that Caretta caretta population growth rates are most affected by adult mortality due to bycatch in shrimp and fish nets (Crouse et al. 1987).

\section{CONCLUSION}

How to reconcile the differences between the ecological and social conceptions of sustainability? The most outstanding result of this study was the apparent difference between the ecological and sociological conceptions of sustainability. In some situations, harvesting levels, considered sustainable by the harvesters, were not ecologically sustainable because overtime they would cause a decline in mangrove population numbers. Furthermore, if the ecological goal is maintaining the mangrove population completely unchanged, then ecologically sustainable harvesting is impossible (e.g., Struhsaker 1998). In this study, even low harvesting intensities that were ecologically sustainable, i.e., positive population growth was maintained, caused significant changes in forest structure. Nonetheless, the undisturbed mangrove population we studied had an annual growth rate of about $4 \%$, suggesting that the population can withstand some harvesting without experiencing a decline in population numbers. Given the local economic situation and the lack of alternative construction materials, mangrove harvesting seems to be a necessity for local people. This situation creates a trade-off between preserving the ecological characteristics that make the mangrove population resilient and responding to human needs. Resolving this situation necessitates creative and practical management solutions.

What are possible management solutions? Unless economic conditions change substantially, it appears that mangrove harvesting will continue in the Río Limón area. It is important that harvesting be conducted in such a manner as to impact the mangrove population as little as possible. Currently, harvesting is concentrated in areas near towns, roads, and waterways that are easily accessible to harvesters (authors' observations). The harvesters should be encouraged to harvest over a broader area. We recommend a conservative harvesting scheme: harvesting no more than $20 \%$ of small adult trees, A1 size class, if no juveniles are extracted, or harvesting up to $20 \%$ of juveniles if small adult harvesting is limited to $10 \%$. A practical metric for harvesters would be to extract 1 out of every 10 adults and saplings in a given spot/yr, or 1 out of 20 adults and 2 out of 10 saplings in a given area. At these harvesting intensities, $\lambda$ would be $>1$. The management system should be adaptive (e.g., Holling 1978); harvesters should be able to respond to feedback from the system, and adjust harvesting levels over time. In healthy mangrove populations, there should be about three small A1 individuals to every two large A3 trees (3:2). A quick indicator of overharvesting is if the ratio of $\mathrm{Al}$ to $\mathrm{A} 3$ trees drops to $2: 2$ or $1: 2$. In such cases, a harvester should look for another location.

Although local knowledge may be imprecise and qualitative, it is based on long-term observations and large sample sizes, making it useful for monitoring the long-term effects of harvesting (Abbot and Guijit 1998, Moller et al. 2004). Older mangrove harvesters reported a decrease in the local availability of the favored size of mangroves for harvesting. Their observations were supported by the scientific data about the effect of harvesting on population stage structures. Because of this consistency between local and scientific knowledge, we believe that harvesters could be effective monitors of the effect of harvesting on the mangroves of Río Limón.

Incorporating harvesters in conservation programs as monitors will address two other concerns identified by this research: (1) that harvesters identified mangrove fecundity is a mechanism for mangrove resilience, whereas the matrix models suggest the mangrove population is insensitive to changes in fecundity and (2) that there may be little intergenerational transfer of knowledge between older and younger harvesters. The trust built from scientist/harvester collaborations might help scientists transmit scientific knowledge about the resilience or susceptibility of mangroves to harvesting. In addition, fostering collaboration between younger and older harvesters in a structured monitoring program may enhance the transfer of knowledge between age groups. 
Responses to this article can be read online at:

http://www.ecologyandsociety.org/voll1/iss2/art14/responses/

\section{Acknowledgments:}

We thank our harvesting informants for participating in this study. We thank F. Barboza, F. Garcia, N. Leviner, A. Loaiza, and M. Lundvik and Instituto de la Conservación del Lago de Maracaibo (ICLAM) for help with field work and logistical support. L. L. H. particularly thanks E. Medina for the introduction to Venezuela's mangroves. We thank D. Cáceres, A. Castillo, S. Díaz, J. Kennedy, J. McKiernan-Gonzales, F. Mora and R. Naylor for comments on the manuscript. Funding was provided by Mellon Mays and NSF fellowships to L. L. H. and dissertation improvement grants from the NSF (\# 0003023), the Morrison Institute, and the Center for Latin American Studies at Stanford University.

\section{LITERATURE CITED}

Abbot, J., and I. Guijt. 1998. Changing views on change: participatory approaches to monitoring the environment. Sustainable Agriculture and Rural Livelihoods (SARL) Discussion Paper Number 2. International Institute for Environment and Development, London, UK.

Alarcón, C. and J. E. Conde. 1993. Mangroves of Venezuela. Pages 211-244 in L. D. Lacerda, editor. Conservation and sustainable utilization of mangrove forests in Latin America and Africa regions. Part 1: Latin America. International Society for Mangrove Ecosystems, Okinawa, Japan.

Alcorn, J. B. and V. M. Toledo. 1998. Resilient resource management in Mexico's forest ecosystems: the contribution of property rights. Pages 216-249 in F. Berkes, C. Folke, and J. Colding, editors. Linking social and ecological systems: management practices and social mechanisms for building resilience. Cambridge University Press, Cambridge, UK.

Armitage, D. 2003. Traditional agroecological knowledge, adaptive management and the sociopolitics of conservation in Central Sulawesi, Indonesia. Environmental Conservation 30:79-90.
Becker, C. D., and K. Ghimire. 2003. Synergy between traditional ecological knowledge and conservation science supports forest preservation in Ecuador. Conservation Ecology 8(1):1.

Berkes, F., and C. Folke. 1998. Linking social and ecological systems for resilience and sustainability. Pages 1-25 in F. Berkes, C. Folke, and J. Colding, editors. Linking social and ecological systems: management practices and social mechanisms for building resilience. Cambridge University Press, Cambridge, UK.

Berkes, F., C. Folke, and J. Colding. 1998. Linking social and ecological systems: management practices and social mechanisms for building resilience. Cambridge University Press, Cambridge, UK.

Brown, K. 2003. Three challenges for a real peoplecentered conservation. Global Ecology and Biogeography 12:89-92.

Caswell, H. 2000. Prospective and retrospective perturbation analyses: their roles in conservation biology. Ecology 81:619-627.

Caswell, H. 2001. Matrix population models: construction, analysis, and interpretation. Second edition. Sinauer Associates, Sunderland, Massachusetts, USA.

Crawley, M. J. 1993. GLIM for ecologists. Blackwell Scientific, Oxford, UK.

Crouse, D. T., L. B. Crowder, and H. Caswell. 1987. A stage-based population model for loggerhead sea-turtles and implications for conservation. Ecology 68:1412-1423.

de Kroon, H., A. Plaisier, J. v. Groenendael, and H. Caswell. 1986. Elasticity: the relative contribution of demographic parameters to the population growth rate. Ecology 67:1427-1431.

Franco, M., and J. Silvertown. 1996. Life history variation in plants: an exploration of the fast-slow continuum hypothesis. Philosophical Transactions of the Royal Society 351:1341-1348.

Gadgil, M., P. R. Seshagiri, G. Utkarsh, P. Pramod, A. Chhatre, and Members of the People's Biodiversity Initiative. 2000. New meanings for old knowledge: the people's 
biodiversity registers program. Ecological Applications 10:1307-1317.

Galue, N. and E. Nucette. 1982. Diagnóstico de los manglares Venezolanos región Zuliana. Ministerio del Medio-Ambiente y Recursos Naturales (MARNR). Serie informe científicos Zona 5/IC/44, Maracaibo.

Ghimire, S., D. McKey, and Y. AumeeruddyThomas. 2004. Heterogeneity in ethnoecological knowledge and management of medicinal plants in the Himalayas of Nepal: implications for conservation. Ecology and Society 9(3):6.

Gil K., C. Casler, and E. Wier. 2003. Biodiversity in Lake Maracaibo. Shell Venezuela, Maracaibo, Venezuela.

Hamilton, L. S., and S. C. Snedaker, editors. 1984. Handbook for mangrove area management. United Nations Environmental Programme, Gland, Switzerland.

Holling, C. S. 1978. Adaptive environmental assessment and management. Wiley and Sons, London, UK.

Huntington, H. 2000. Using traditional ecological knowledge in science: methods and applications. Ecological Applications 10(5):1270-1274.

Lacerda, L. D., editor. 2002. Mangrove ecosystems: function and management. SpringerVerlag, Berlin, Germany.

Lefkovitch, L. P. 1967. A theoretical evaluation of population growth after removing some individuals from some age groups. Bulletin of Entomological Research 57:437-445.

López-Hoffman L, J. L. DeNoyer, I. Monroe, R. Shaftel, N. P. R. Anten, M. Martinez-Ramos, and D. D. Ackerly. 2006. Mangrove seedling net photosynthesis, growth, and survivorship are interactively affected by salinity and light. Biotropica, in press.

Mackinson S, and L. Nottestad. 1998. Combining local and scientific knowledge. Reviews in Fish Biology and Fisheries 8:481-490.

Moller, H., F. Berkes, P. O. Lyver, and M. Kislalioglu. 2004. Combining science and traditional ecological knowledge: monitoring populations for co-management. Ecology and Society 9(3):2.

Narváez, E. M. 1998. Estructura y composición de los manglares de Caño Paijana. Thesis. Universidad Autónoma del Estado de Zulia, Maracaibo, Venezuela.

Newton, J. L., and E. Freyfogle. 2005. Sustainability: a dissent. Conservation Biology 19:23-32.

Oficina Central de Estadistica e Information (OCEI). 1990. Anuario Estadístico de las Comunidades Indígenas de Venezuela. OCEI, Caracas, Venezuela.

Oficina Central de Estadistica e Informacion (OCEI). 2002. Anuario Estadístico de Venezuela 2000. OCEI, Caracas, Venezuela.

Silvertown, J. 1987. Introduction to plant population demography. Longman Scientific and Technical, Harlow, Essex, UK.

Smith, T. J. 1992. Forest structure. Pages 101-136 in A. I. Robertson and D. M. Alongi, editors. Tropical mangrove ecosystems. American Geophysical Union, Washington, D.C., USA.

Struhsaker, T. T. 1998. A biologist's perspective on the role of sustainable harvest in conservation. Conservation Biology 12(4):930-932.

ter Braak, C. J. F. 1987. Ordination. Pages 91-173 in R. H. G. Jongman, C. J. F. ter Braak, and O. F. R. van Tongren, editors. Data analysis in community and landscape ecology. Cambridge University Press, Cambridge, UK.

Turner, N. J, M. B. Ignace, and R. Ignace. 2000. Traditional ecological knowledge and wisdom of aboriginal peoples in British Columbia. Ecological Applications 10(5):1275-1287.

Usher, M. B. 1969a. A matrix approach to the management of renewable resources, with special reference to selection forests: two extensions. Journal of Applied Ecology 6:347-348.

Usher, M. B. $1969 b$. A matrix model for forest management. Biometrics 25:309-315. 
APPENDIX 1. Model parameterization and analysis, and background on matrix models.

To construct stage-based population projection matrices, it is first necessary to estimate the average "vital rates" for each stage class. The vital rates are: a) Permanence, the probability an individual will survive one year and remain in its starting stage class; b) Transition, the probability that an individual will survive and grow into another stage class during the course of the year; and c) Fecundity, the annual reproductive output of an individual (Caswell 2001).

The heights and diameters of all juveniles and adult trees within the transects were measured in June 1999 and remeasured in 2000 and 2001. We determined that an adult or juvenile had transitioned to another size class if its diameter increased (or decreased) enough to qualify for that size class. For seedling transition and survival, from June 1999 to 2001 we followed seedlings in 24 plots $\left(3.14 \mathrm{~m}^{2}\right)$ randomly located within $15 \mathrm{~m}$ of the main transects. We measured the height of a maximum of 20 seedlings per plot. At the end of the year, if a seedling had grown taller than $70 \mathrm{~cm}$, we considered that it had transitioned to the juvenile class. Juvenile and seedling survivorship was determined by presencel absence at the last census. Adults were determined to be dead if they were uprooted and/or the great majority of their leaves were dry. Using the aforementioned data, we determined the mean permanence and transition rates for each size class.

We used the annual rate of seedling establishment in the plots to estimate fecundity, where fecundity was the average number of seedlings per hectare per individual per adult size class that established within one year. Fecundity was apportioned among adult size classes as follows: We estimated a linear relationship between tree crown size and trunk diameter $\left(\mathrm{y}=4.349 \mathrm{x}-39.496, \mathrm{R}^{2}=0.91, \mathrm{p}=0.01\right)$ and assumed that an individual tree's fecundity was proportional to its crown size. We then determined the mean fecundity per size class.

Population projection matrices have the form: $\mathbf{n}(\mathbf{t}+\mathbf{1})=\mathbf{A} \times \mathbf{n}(\mathbf{t})$, where $\mathbf{n}(\mathbf{t})$, represents the stage structure (n) at time $\mathbf{t}, \mathbf{n}(\mathbf{t}+\mathbf{1})$ is the stage structure at the next time interval (the same time the next year), and $\mathbf{A}$ is a matrix containing the vital rate averages for each stage class. We used the bootstrap resampling procedure recommended by Caswell (2001) to estimate $\lambda$ (the finite population growth rate) and confidence intervals (CIs) for $\lambda$ and the matrix elasticities. In this method, each observation in the bootstrap is one individual and its corresponding history (i.e. vital rates). In each run of the bootstrap, one observation per size class was randomly sampled with replacement for a total of five total observations resampled per run. The remaining observations were used to construct matrix A. We then used standard, numerical, iterative techniques for estimating $\lambda$ (Caswell 2001). Each value for $\lambda$ and the elasticities was obtained after 256 iterations. This was repeated 2000 times for a bootstrap distribution of $\lambda$ and elasticity values. We used the normal theory parametric method to estimate $\lambda$ and $95 \%$ CIs (Caswell 2001) because it gave similar estimates for $\lambda$ but larger, more conservative $95 \%$ CIs than the bootstrap percentile intervals method (Caswell 2001). 